Article

\title{
Spatiotemporal Variability in Start and End of Growing Season in China Related to Climate Variability
}

\author{
Quansheng Ge, Junhu Dai, Huijuan Cui and Huanjiong Wang * \\ Key Laboratory of Land Surface Pattern and Simulation, Institute of Geographical Sciences and Natural \\ Resources Research, Chinese Academy of Sciences, 11A, Datun Road, Chaoyang District, Beijing 100101, China; \\ geqs@igsnrr.ac.cn (Q.G.); daijh@igsnrr.ac.cn (J.D.); cuihj@igsnrr.ac.cn (H.C.) \\ * Correspondence: wanghj@igsnrr.ac.cn; Tel.: +86-10-6488-9831
}

Academic Editors: Roberto Colombo, Clement Atzberger and Prasad S. Thenkabail Received: 9 March 2016; Accepted: 18 May 2016; Published: 23 May 2016

\begin{abstract}
Satellite-derived vegetation phenophases are frequently used to study the response of ecosystems to climate change. However, limited studies have identified the common phenological variability across different climate and vegetation zones. Using NOAA/Advanced Very High Resolution Radiometer (AVHRR) Normalized Difference Vegetation Index (NDVI) dataset, we estimated start of growing season (SOS) and end of growing season (EOS) for Chinese vegetation during the period 1982-2012 based on the Midpoint method. Subsequently, the empirical orthogonal function (EOF) analysis was applied to extract the main patterns of phenophases and their annual variability. The impact of climate parameters such as temperature and precipitation on phenophases was investigated using canonical correlation analysis (CCA). The first EOF mode of phenophases exhibited widespread earlier or later SOS and EOS signals for almost the whole country. The attendant time coefficients revealed an earlier SOS between 1996 and 2008, but a later SOS in 1982-1995 and 2009-2012. Regarding EOS, it was clearly happening later in recent years, mainly after 1993. The preseason temperature contributed to such spatiotemporal phenological change significantly. The first pair of CCA patterns for phenology and preseason temperature was found to be similar and its time coefficients were highly correlated to each other (correlation coefficient $>0.7$ ). These results indicate that there is a substantial amount of common variance in SOS and EOS across different vegetation types that is related to large-scale modes of climate variability.
\end{abstract}

Keywords: remote sensing phenology; growing season; NDVI; canonical correlation analysis

\section{Introduction}

Because plants are equipped with a phenotypic plasticity, they can grow and develop in changing environmental conditions as long as the conditions do not alter beyond the tolerances of the species [1]. Among various types of phenotypic plasticity (e.g., morphological, physiological, behavioral, phenological), phenology is particularly sensitive to small variations in environmental factors [2]. Recent meta-analyses showed that most time series of spring phenophases (e.g., flowering and leaf unfolding time of plants) arrived earlier in response to climate warming over the past several decades, and the magnitude of these advances are comparable across continents [3-5]. Regarding phenophases of plant senescence, the overall trend is towards later phenophases mainly due to the remarkable autumn warming, but the trends were less apparent and exhibited distinct regional difference [6]. Plant phenology not only responds to climate change, but also controls many feedbacks of vegetation to the climate system $[7,8]$. The change in plant phenology can change surface roughness length and albedo, further impacting sensible and latent heat flux as well as water flux from surface to 
the atmosphere [9]. In addition, extended growing season length may affect terrestrial carbon cycle and thus global temperature [10-12]. Therefore, plant phenology has attracted ever-increasing attention in the fields of ecology and climatology over the past few years.

There are two commonly used approaches to monitoring plant phenology [13]. Manual observation on the ground can provide phenological information about various phenophases of specific plant species with high temporal resolution, but it cannot cover continuously the entire geographic area [14]. Satellite-derived phenology offers important complementarity to ground observation because it can provide vegetation phenological information with full spatial coverage at the landscape level [15]. The seasonal pattern of variation in vegetated land surfaces based on satellite data was termed as remote sensing phenology [16] or land surface phenology (LSP) [17], which can offer several key phenological variables including the start of the growing season (SOS) and end of growing season (EOS). In contrast to the ground phenophases, SOS and EOS could represent spatially integrated date of green-up onset or dormancy onset for all plant species at each pixel. To date, most phenological studies at a regional or global scale are based on satellite data. For example, analyses from Advanced Very High Resolution Radiometer (AVHRR) Normalized Difference Vegetation Index (NDVI) data showed that green-up date was advanced and dormancy onset date was delayed in China from 1982 to $2010[18,19]$. In Europe, changes in the NDVI-derived EOS contributed more to the extension of growing season than changes in spring green-up date from 1982-2011 [20]. A similar conclusion was also found in North America [21]. In Africa, significant greening/browning trends for several regions were found, and could be attributed to both climatic and non-climatic drivers [22]. Furthermore, at the hemispheric or global scale, long-term trends of LSP have been detected using different satellite datasets [23-25].

The previous LSP studies mostly analyzed the temporal trends in phenological phases, and correlated the phenological metrics to climate variables for each pixel $[23,25,26]$. Furthermore, they also analyzed phenological trends or sensitivities to climate change for a group of pixels belonging to a given vegetation type or geographical region. Thus, lots of information about spatial difference in phenological responses had acquired. However, few studies have examined whether a common variability existed across geographical regions or ecosystems. It will reveal the answer if there is a general climate forcing for the observed interannual variability in phenology that is independent of geographic or vegetation zones at a large scale. Empirical orthogonal function (EOF) analysis is an effective method to address this question, since it could identify the most extensive spatial patterns of year-to-year variability in phenology. Thus far, EOF analysis has been applied to phenophases of several plants species based on ground phenological observations $[27,28]$. However, to our knowledge, few studies applied EOF analysis to LSP.

China is a suitable region to study the common variability in LSP since it encompasses a wide range of ecosystems and climate types along latitudinal and altitudinal gradients [29]. The objectives of this study are: (i) to examine whether different vegetation types have similar phenological variability across space; and (ii) to quantify the contribution of climate variables to spatial patterns of phenological variability. To that end, we assess the most important patterns of phenological variability in China from 1982 to 2012, and examine the linkage between phenophases and climate variables such as temperature and precipitation.

\section{Materials and Methods}

\subsection{Data Sources}

NDVI can be related to leaf area index and the absorption of photosynthetically active radiation by plant canopies [30]; it is thus widely used in studies about LSP [31,32]. In this study, an AVHRR NDVI dataset, developed by the global inventory modeling and mapping studies (GIMMS) group at NASA Goddard Space Flight Center, were used [33]. This dataset was called NDVI3g, which assembled NDVI time series from different AVHRR sensors, accounting for various deleterious effects, such as 
calibration loss, orbital drift, volcanic eruptions, etc. It has a spatial resolution of $1 / 12^{\circ}$ and a 15 -day temporal resolution, which is available from 1982 to 2012.

A 1:1,000,000 vegetation map was used for determining the vegetation type at each pixel in the NDVI3g dataset [34]. As shown on the map, the vegetations in China are categorized into 11 types: needleleaf forest, needleleaf and broadleaf mixed forest, broadleaf forests, scrub, grass-forb community, steppe, meadow, swamp, alpine vegetation, desert vegetation, and cultivated vegetation (Figure 1).

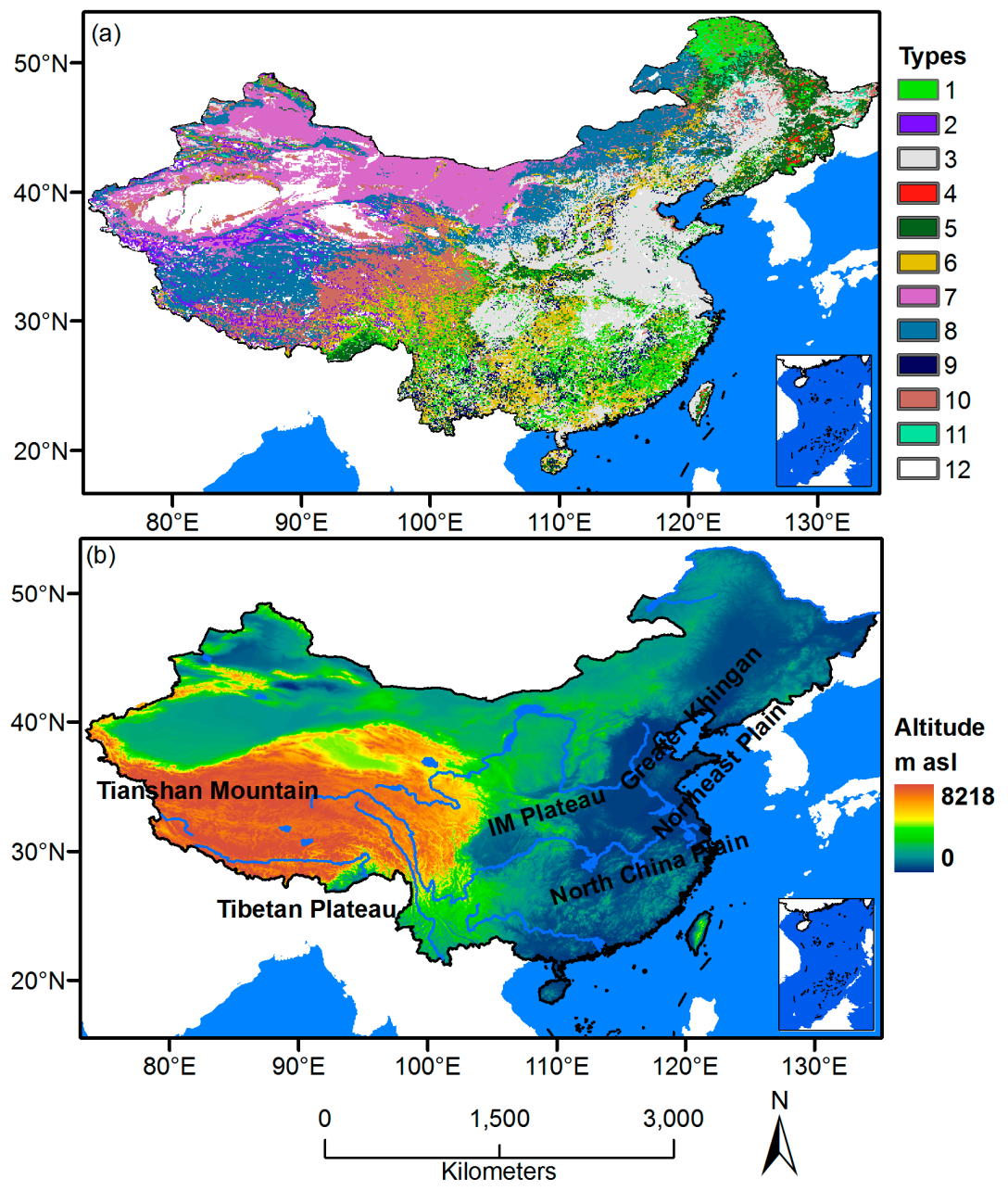

Figure 1. Vegetation types and topography of China. (a) Vegetation types: 1, needleleaf forest; 2 , alpine vegetation; 3 , cultivated vegetation; 4 , mixed forest; 5 , broadleaf forest; 6 , scrub; 7 , desert vegetation; 8, steppe; 9 , grass-forb community; 10 , meadow; 11, swamp; 12 , nonvegetated area; (b) Geographical regions mentioned in the text are labeled in bold letters. IM Plateau represents Inner Mongolia Plateau.

Regarding the climate data, we chose the China Meteorological Forcing (CMF) dataset [35], because it has comparable spatial resolution with the NDVI3g dataset. The CMF dataset was developed by the Data Assimilation and Modeling Center for Tibetan Multi-Spheres, Institute of Tibetan Plateau Research, Chinese Academy of Sciences. This dataset currently covers the period of 1979-2012. Its spatial resolution is $1 / 10^{\circ}$, and temporal resolution is $3 \mathrm{~h}$. Two variables including surface temperature and precipitation were extracted from the dataset, and the original 3-h data were merged with monthly data. The climate parameters (temperature and precipitation) at each pixel in the NDVI3g dataset were extracted as the value at the nearest pixel of the CMF dataset. 


\subsection{Methods}

\subsubsection{Estimation of the Start and End of Growing Season}

Prior to estimate SOS or EOS, we first removed cloud-contaminated points in the NDVI time series, which were marked by the highest $5 \%$ and the lowest $5 \%$ of values among all annual time series from 1982-2012 in each pixel. Furthermore, our analysis only included pixels whose multi-year median NDVI time series simultaneously met the following criteria:

(1) Annual maximum NDVI $>0.15$ and mean annual NDVI $>0.10$ [36]. Such thresholds excluded deserts and sparsely vegetated areas, where the soil background would noticeably impact the spectral signals of vegetation.

(2) The vegetation type should be natural vegetation, since the phenology of cultivated vegetation is strongly impacted by human activities [37].

(3) The annual maximum NDVI occurred between June and September; mean NDVI of July to August $>1.35 \times$ NDVI of November to December; mean NDVI of July to August $>1.35 \times$ NDVI of January to February [36]. These criteria excluded the vegetation lack of seasonality, e.g., the evergreen vegetation over the humid tropics and subtropics, where aberrant NDVI fluctuation related to weather impact often occurred [37].

As a result, 34.0\% of total pixels were included in the following analyses (Table 1). All pixels from cultivated vegetation and nonvegetated areas, and most parts of desert vegetation and grass-forb communities were excluded.

Table 1. Number of pixels and the percentage of pixels meeting the screening criteria for each vegetation type.

\begin{tabular}{ccccc}
\hline Code & Vegetation Types & Number of Pixels & Number of Pixels Analyzed & Percentage \\
\hline 1 & Needleleaf forest & 11,349 & 3882 & $34.2 \%$ \\
2 & Alpine vegetation & 4581 & 1892 & $41.3 \%$ \\
3 & Cultivated vegetation & 30,158 & 0 & $0.0 \%$ \\
4 & Mixed forest & 362 & 299 & $82.6 \%$ \\
5 & Broadleaf forests & 10,309 & 6405 & $62.1 \%$ \\
6 & Scrub & 12,361 & 4664 & $37.7 \%$ \\
7 & Desert vegetation & 18,379 & 2433 & $13.2 \%$ \\
8 & Steppe & 20,806 & 13,125 & $63.1 \%$ \\
9 & Grass-forb community & 3936 & 737 & $18.7 \%$ \\
10 & Meadow & 14,888 & 12,351 & $83.0 \%$ \\
11 & Swamp & 1131 & 1069 & $94.5 \%$ \\
12 & Nonvegetated area & 9466 & 0 & $0.0 \%$ \\
\hline
\end{tabular}

For each pixel meeting the above criteria, we employed the Midpoint method to retrieve annual SOS and EOS. Although there are a number of methods to derive the SOS and EOS from NDVI time series [18,38], several studies found that the SOS derived from the Midpoint method was more closely related to ground-based spring phenophases of plants than other methods in North America [38], Europe [14] and China [39]. In this method, the multi-year median NDVI time series at each pixel is calculated (Figure 2), so as to eliminate the impact of extremely high or low NDVI values. Afterwards, a threshold is defined as the midpoint between the minimum and maximum NDVI value in the median NDVI time series. In each year, the first crossing of this threshold was marked as the SOS, and the last crossing of this threshold was marked as the EOS (Figure 2). Thus, in this method, the threshold for determining SOS and EOS is constant over time, but varies among different pixels. 


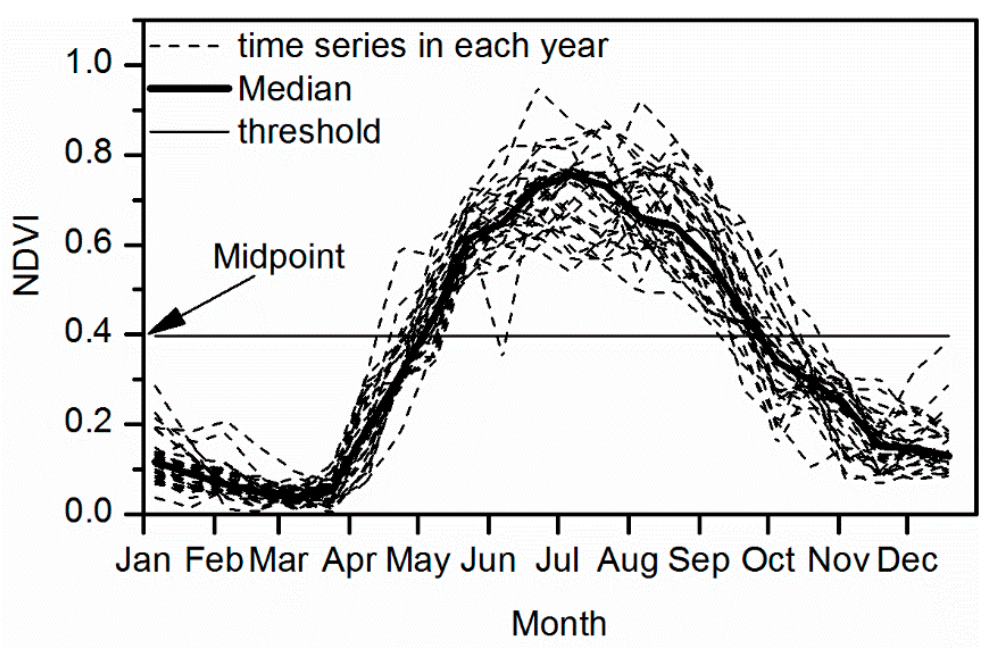

Figure 2. Method for retrieving SOS and EOS using NDVI time series. In each year, the first crossing of threshold (defined by midpoint of median time series) marks the SOS, and the last crossing of this threshold marks the EOS.

Since the neighboring pixels were in very similar climate conditions, they would have similar SOS or EOS rather than abrupt changes. Therefore, we used a $7 \times 7$ median filter to remove noise in the derived SOS or EOS images. In addition, for the SOS or EOS time series in each pixel, the dates were considered as outliers if the estimated residuals of the linear models (between phenophases and years) were larger than or equal to 30 days [40]. These outliers were replaced with long-term mean (1982-2012) [28].

\subsubsection{Empirical Orthogonal Function (EOF) Analysis}

Prior to the EOF analysis, the SOS and EOS time series in each pixel were firstly transformed to anomalies through subtracting the multi-year average (1982-2012). The climate parameters during one or two months before the mean phenophases (also referred to as preseason) affect phenological events most markedly according to previous studies [4,41-43]. Therefore, the length of preseason was chosen to be two months. If the mean SOS or EOS occurred in the first half of the month, preseason was referred to the preceding two months; but if the mean SOS or EOS occurred in the latter half of the month, preseason was referred to the current month and previous month. In each pixel, preseason temperature and precipitation were then calculated as the average of daily temperature and sum of daily precipitation during the preseason period, respectively. Similar to the phenophases, the preseason temperature and precipitation were also transformed to anomalies through subtracting the multi-year average (1982-2012).

Subsequently, we used empirical orthogonal function (EOF) analysis to identify the most extensive and influential patterns of year-to-year variability in phenology and climate parameters [44]. Assuming that $X_{s, t}$ denotes the climate matrix (preseason temperature or precipitation) and $Y_{r, t}$ denotes the phenology matrix (SOS or EOS), where the subscripts $s(s=1,2,3, \ldots, m)$ and $r(r=1,2,3, \ldots, n)$ represent space, and subscript $t$ represents time $(t=1,2,3, \ldots, k)$, EOF analysis can be expressed as:

$$
\begin{aligned}
& X_{s, t}=F_{s, s} T_{s, t} \\
& Y_{r, t}=F_{r, r} T_{r, t}
\end{aligned}
$$

where $F_{s, s}$ and $F_{r, r}$ represent EOF spatial modes of the climate and phenology matrices, respectively. $T_{s, t}$ and $T_{r, t}$ are their attendant time coefficients, which are also referred to as principal components (PCs). In this study, $k$ equals 31 (the length of study period 1982-2012); $m$ and $n$ equal to 46,857 (the number of pixels meeting the above criteria). 


\subsubsection{Canonical Correlation Analysis (CCA)}

EOF analysis can be only used to investigate the dominant modes of variability for each variable separately. Aiming to analyze the relationship between climate and phenological variables, we further applied the canonical correlation analysis (CCA), which was suitable for investigating the relationship between two multidimensional datasets [45]. Prior to the CCA, for simplicity, the original datasets were approximated by the first $i$-th EOF modes of the climate dataset $\left(F_{s, i}, i<m\right)$ and the first $j$-th EOF modes of the phenology dataset $\left(F_{r, j}, j<n\right)$ :

$$
\begin{aligned}
& \hat{X}_{s, t}=F_{s, i} T_{i, t} \\
& \hat{Y}_{r, t}=F_{r, j} T_{j, t}
\end{aligned}
$$

where $\hat{X}_{s, t}$ and $\hat{Y}_{r, t}$ are the approximation of the original datasets $X_{s, t}$ and $Y_{r, t}$, respectively. Since the first EOF mode of SOS and EOS can represent large-scale variability (see "Results" section), we set $j=1$. Regarding the climate datasets, $i$ was set as 5 , because the climate pattern comparable to the phenological pattern may be identified through combination of several EOF modes.

In the next step, CCA was performed to calculate canonical vectors $\left(C_{i, q}\right.$ and $\left.D_{j, q}\right)$ and CCA time coefficients $\left(U_{q, t}\right.$ and $\left.V_{q, t}\right)$ :

$$
\begin{aligned}
& U_{q, t}=C_{i, q}^{\prime} T_{i, t} \\
& V_{q, t}=D_{j, q}^{\prime} T_{j, t}
\end{aligned}
$$

where $U_{q, t}$ and $V_{q, t}$ are CCA time coefficients of climate and phenology, respectively. $q$ is equal to $i$ or $j$, whichever is smaller ( $q=1$ here). $U_{q, t}$ and $V_{q, t}$ should meet the following conditions [46]: (1) correlations between any two rows of $U_{q, t}$ are zero; correlations between any two rows of $V_{q, t}$ are zero; correlations between any one row of $U_{q, t}$ and any one row of $V_{q, t}$ are zero if their row numbers are different; (2) the correlation between the first row of $U_{q, t}$ and $V_{q, t}$ is maximum; (3) the correlation between second row of $U_{q, t}$ and $V_{q, t}$ is the maximum under the constraints of (1) and (2). The correlations for the higher indexed pairs of coefficients satisfy similar constraints. The detailed algorithm to calculate $C$ and $D$ was described in von Storch [46].

Two new variables $W$ and $Z$ were introduced as the generalized inverse of matrix $C$ and $D$, that is, $W$ and $Z$ satisfy the following equations:

$$
\begin{aligned}
& W_{i, q} C_{i, q}^{\prime}=E_{i, i} \\
& Z_{j, q} D_{j, q}^{\prime}=E_{j, j}
\end{aligned}
$$

where $E_{i, i}$ is $i \times i$ identity matrix and $E_{j, j}$ is $j \times j$ identity matrix.

When following Equations (5) and (7), the time coefficients of climate $\left(T_{i, t}\right)$ can be expressed as:

$$
W_{i, q} U_{q, t}=T_{i, t}
$$

Similarly, following Equations (6) and (8), the time coefficients of phenology $\left(T_{j, t}\right)$ can be expressed as:

$$
Z_{j, q} V_{q, t}=T_{j, t}
$$

Finally, we could express $\hat{X}_{s, t}$ and $\hat{Y}_{r, t}$ by using CCA time coefficients $\left(U_{q, t}\right.$ and $\left.V_{q, t}\right)$. Following Equations (3) and (9),

$$
\hat{X}_{s, t}=\left(F_{s, i} W_{i, q}\right) U_{q, t}
$$

Following Equations (4) and (10),

$$
\hat{Y}_{r, t}=\left(F_{r, j} Z_{j, q}\right) V_{q, t}
$$


where $F_{s, i} W_{i, q}$ is the CCA patterns for climate. The $k$-th column of $F_{s, i} W_{i, q}$ represents the $k$-th CCA pattern of climate. $U_{q, t}$ is the CCA coefficient of climate. The $k$-th row of $U_{q, t}$ represents the time coefficient of the $k$-th CCA pattern. Similarly, $F_{r, j} Z_{j, q}$ represents the CCA patterns of phenology and $V_{q, t}$ is the corresponding CCA coefficient. In this study, we only analyzed the first EOF mode of phenology (i.e., $j=q=1$ ). Therefore, the first CCA pattern of phenology is identical with the first EOF mode of phenology.

The above CCA was performed four times for each pair of phenology and climate dataset. The last step was analyzing the relationship between CCA time coefficients of phenology and climate. Meanwhile, similarities between CCA patterns of phenology and climate were examined.

\section{Results}

\subsection{EOF Analyses}

The EOF analyses on the phenology and the climate variables showed clear differences in the explained variances (Table 2). The first EOF mode could explain $17 \%$ of the variance in the SOS data, while the five leading EOF modes together accounted for $53 \%$ of the year-to-year variance in the SOS. Regarding EOS, the dominance of the first EOF mode was a little more pronounced with $19 \%$ explained variability, while the five leading spatial patterns together explained $44 \%$ of the variance in the EOS.

With regard to preseason temperature of SOS and EOS, the first EOF mode could account for $46 \%$ and $50 \%$ of the variance, respectively (Table 2). For preseason precipitation of SOS and EOS, the dominance of the first EOF mode was less pronounced with only $20 \%$ and $18 \%$ explained variability, respectively.

Table 2. Variance explained by the five leading EOF modes of phenology, preseason temperature and precipitation.

\begin{tabular}{cccc}
\hline EOF Mode & Phenology & Temperature & Precipitation \\
\hline \multicolumn{4}{c}{ Start of growing season } \\
\hline 1 & 0.17 & 0.46 & 0.20 \\
2 & 0.14 & 0.20 & 0.13 \\
3 & 0.10 & 0.11 & 0.09 \\
4 & 0.07 & 0.04 & 0.07 \\
5 & 0.05 & 0.03 & 0.05 \\
\hline Sum & 0.53 & 0.84 & 0.54 \\
\hline & End of growing season \\
\hline 1 & 0.19 & 0.50 & 0.18 \\
2 & 0.08 & 0.12 & 0.14 \\
4 & 0.06 & 0.08 & 0.10 \\
5 & 0.06 & 0.05 & 0.08 \\
Sum & 0.05 & 0.05 & 0.06 \\
\hline
\end{tabular}

\subsection{Dominant Phenological Patterns and Their Time Evolutions}

The leading EOF mode of SOS showed a relatively homogeneous structure with the strongest weights over the Tibetan plateau (Figure 3a). Except in a few pixels located in the Northeastern Plain, the EOF weights were almost consistently negative, suggesting an earlier or later SOS for the whole country, depending on the PC value. Thus, different vegetation types had similar variability of SOS across space. The yearly variations of the leading EOF mode are shown in Figure 4a. The time evolution of SOS experienced three stages. From 1982 to 1996, the SOS was on average 0.7 days later than the long-term mean. Between 1997 and 2008, the anomalies of SOS were negative, indicating an advance of 1.2 days. After 2008, the SOS occurred about 1 day later than the long-term mean. 
The overall linear trend found in the first EOF mode was 0.6 days per decade towards earlier SOS (Figure 4a).

In contrast to the first EOF mode of SOS, the second EOF mode revealed considerable regional patterns (Figure 3b). In the Northeastern Plain, the EOF weights changed from negative values in the north to positive values in the south. In addition, most pixels in the Tibetan Plateau showed negative EOF weights, while most pixels in the North China Plain showed positive weights (Figure 3b). Such North-South and altitude patterns seemed more pronounced in 2009-2012, as revealed in the PC time series (Figure $4 b$ ).

With regard to the EOS, the leading EOF mode represented a broad region of common variability with the strongest weights over Tianshan Mountains and the southeastern edge of the study area (Figure 3c). Only in a few pixels of the Greater Khingan Range and the northwestern Tibetan Plateau did the EOF weights show opposite phenological shifting. Generally, different vegetation types had common variability of EOS. The PC time series of the leading EOF is shown in Figure 4c. A clear change of direction in EOS occurred around 1993. During the period of 1982-1993, the EOS was about 0.8 days earlier than the long-term mean, which shifted to 0.5 days later than the long-term mean during the period of 1994-2012. Overall, the linear trend of EOS during the whole study period was 0.7 days per decade (Figure $4 \mathrm{c}$ ).

The second EOF mode of EOS also revealed certain regional patterns (Figure 3d). Especially in the eastern edge of the Tibetan and Inner Mongolia Plateau, the direction of the change in EOS was contrary to the other parts of the country. According to the corresponding PC time series (Figure 4d), the second EOF mode of EOS revealed no considerable temporal trend.

(a) SOS EOF1

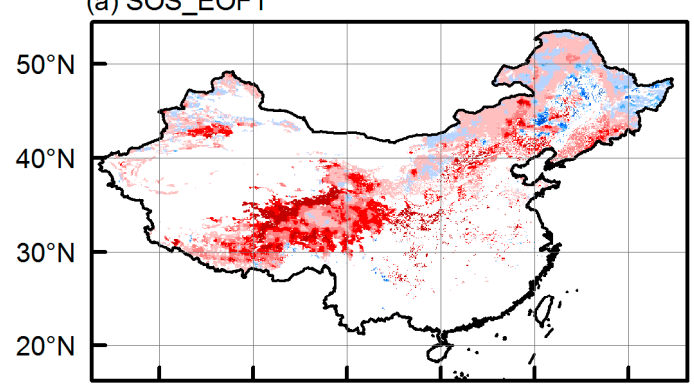

(c) EOS_EOF1

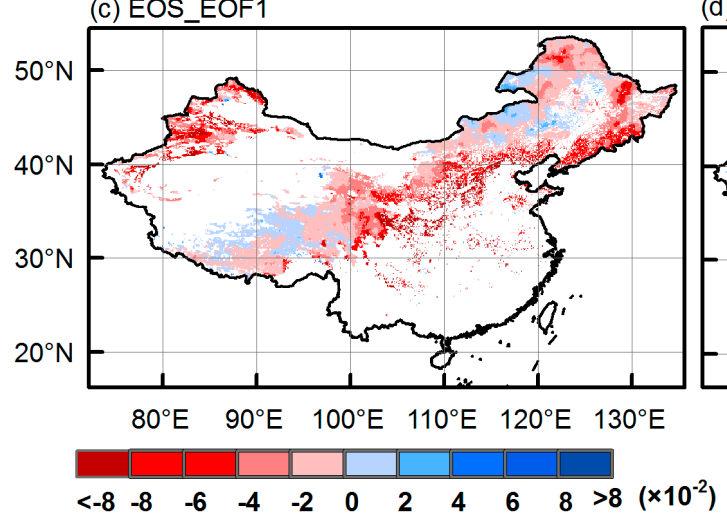

(b) SOS_EOF2

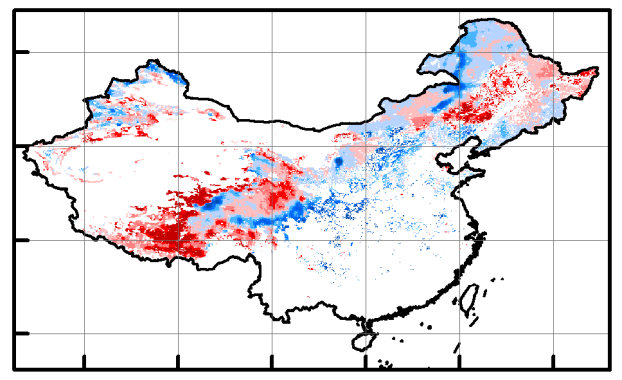

(d) EOS_EOF2

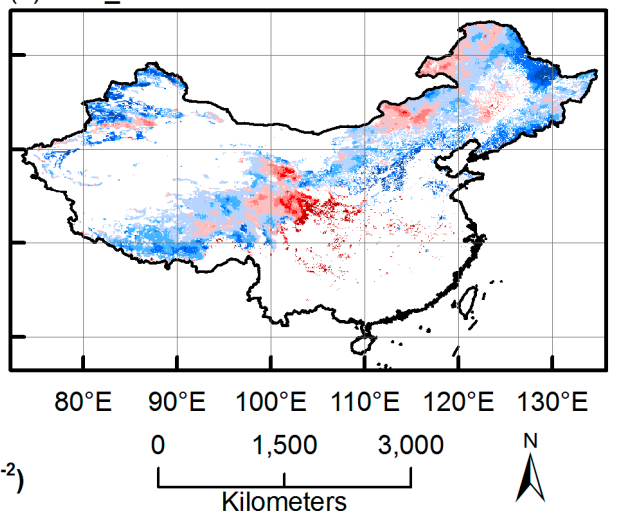

Figure 3. The first and second EOF modes of start of growing season $(\mathbf{a}, \mathbf{b})$ and end of growing season $(\mathbf{c}, \mathbf{d})$ in China. The EOF weights are dimensionless parameters. 
(a) SOS PC1

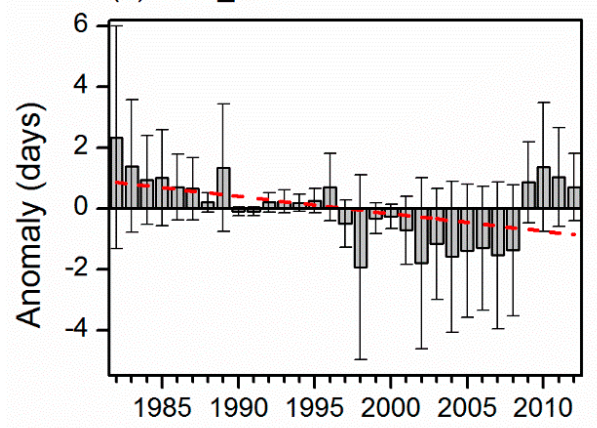

(c) EOS_PC1

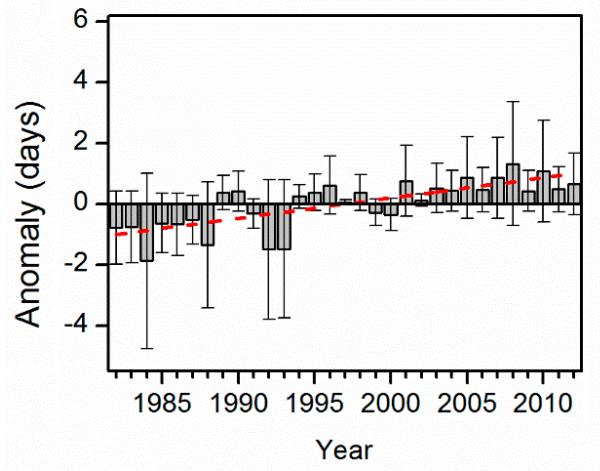

(b) SOS_PC2

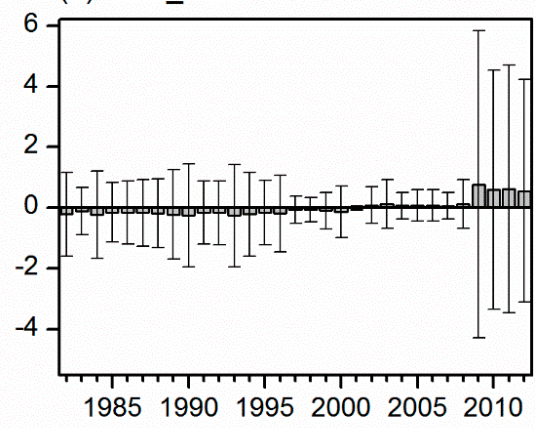

(d) EOS_PC2

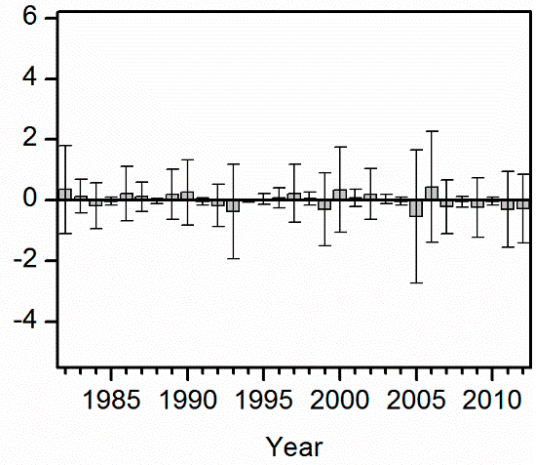

Figure 4. PC time series for EOF modes of SOS and EOS from 1982 to 2012 in China. All PC values are scaled to anomalies in days by multiplying mean value of EOF weights in Figure 3. (a) PC time series for the first EOF mode of SOS. The dashed line shows the regression line $(\mathrm{y}=-0.05722 \mathrm{x}+114.27$, $R^{2}=0.22, p<0.01$ ); (b) PC time series for the second EOF mode of SOS; (c) PC time series for the first EOF mode of EOS. The dashed line shows the regression line $\left(\mathrm{y}=0.06656 \mathrm{x}-132.91, R^{2}=0.55, p<0.01\right)$; (d) PC time series for the second EOF mode of EOS.

\subsection{CCA Patterns and Time Coefficients of Climate and Phenology}

The first pair of derived CCA patterns for preseason temperature and SOS is shown in Figures 3a and $5 a$, respectively. The first CCA pattern of temperature represented a mode of a ubiquitous warming across almost the whole country (Figure 5a), corresponding to the ubiquitous earlier SOS in the first CCA pattern of SOS (Figure 3a). Moreover, the CCA time coefficients of SOS were significantly correlated with that of temperature (Figure $5 b, R=0.71, p<0.01$ ), suggesting the interannual change in SOS pattern highly depended on the interannual change in temperature pattern.

Figures $3 a$ and $5 c$ display the CCA patterns of preseason precipitation and SOS in the first canonical mode, respectively. In the southeastern part of the study area, precipitation anomalies revealed in the CCA pattern tended to be negative, while the precipitation anomalies tended to be positive in the northwestern part of the study area (Figure 5c). However, the CCA pattern of SOS revealed ubiquitous earlier SOS across the country (Figure 3a). These results suggested that the role of precipitation in regulating SOS varied among different geographical regions. Furthermore, the relationship between CCA time coefficients of SOS and precipitation was significant but weaker than temperature (Figure $5 \mathrm{~d}, R=0.58, p<0.01$ ). 
(a) CCA pattern of temperature

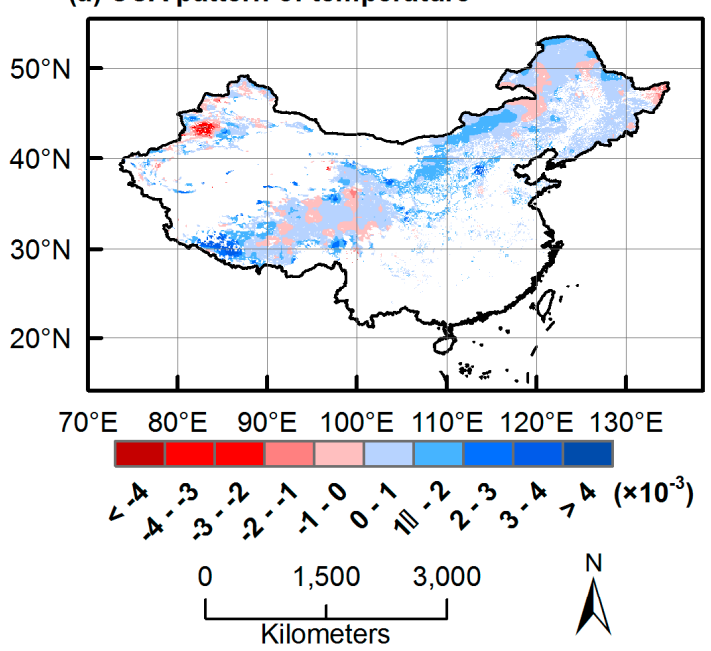

(c) CCA pattern of precipitation

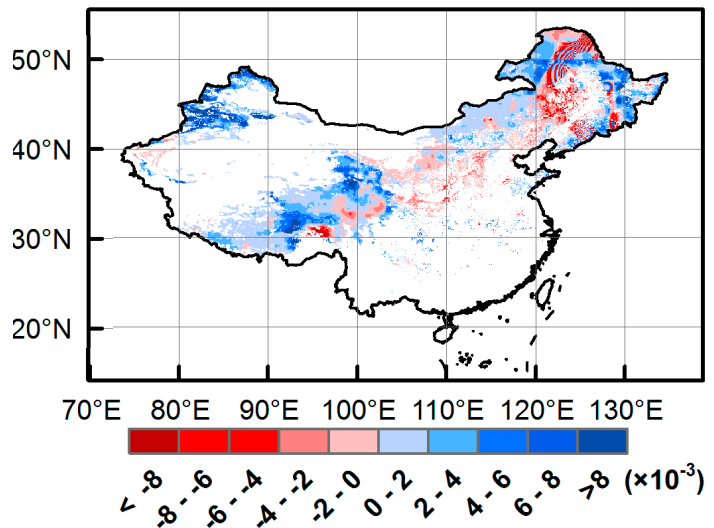

(b) CCA coefficients of SOS and T

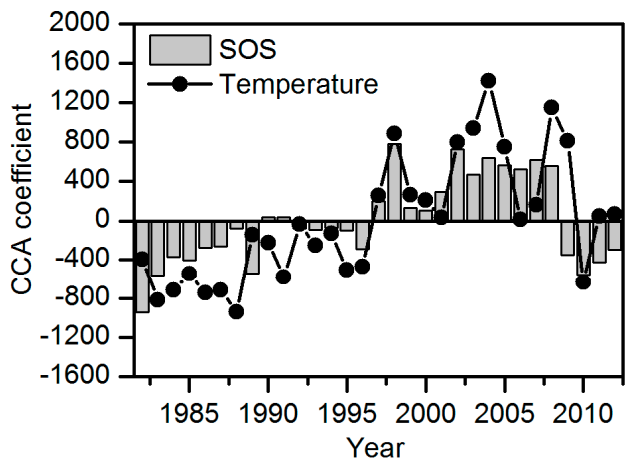

(d) CCA coefficients of SOS and P

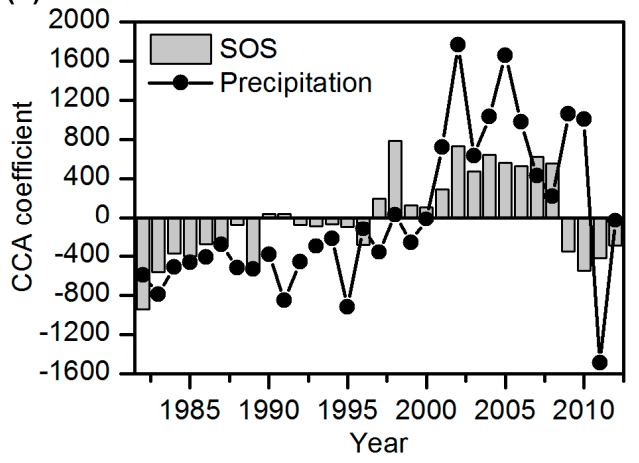

Figure 5. The CCA patterns and time coefficients between climate variables and start of growing season (SOS). (a) First CCA pattern of preseason temperature when performing CCA between SOS and preseason temperature; CCA pattern of SOS corresponded with CCA pattern of temperature is shown in Figure 3a; (b) CCA time coefficients of SOS and preseason temperature $(R=0.71, p<0.01)$; (c) First CCA pattern of preseason precipitation when performing CCA between SOS and preseason precipitation; CCA pattern of SOS corresponded with CCA pattern of precipitation is shown in Figure 3a; (d) CCA time coefficients of SOS and preseason precipitation $(R=0.58, p<0.01)$. The CCA weights and time coefficients are dimensionless parameters. The products of CCA weights and time coefficients are the phenological anomalies (days).

The results of CCA between preseason temperature and EOS showed a relatively homogeneous structure in both temperature and phenological patterns. The negative temperature anomalies distributing uniformly almost over the entire area (Figure 6a, except a few pixels in northeastern China and Tibetan Plateau), is associated with an earlier EOS (Figure 3c). Additionally, significant correlation can be found between CCA time coefficients of EOS and temperature (Figure $6 \mathrm{~b}, R=0.79$, $p<0.01$ ).

Through canonical correlation analysis between preseason precipitation and EOS, the consequent CCA pattern of precipitation (Figure 6c) was more complex than that of EOS (Figure 3c). In most pixels of the Tibetan Plateau and the North China Plain, precipitation anomalies are negative, while precipitation anomalies are positive in other regions of China (Figure 6c). Although the CCA time coefficients of EOS were significantly associated with those of precipitation, the correlation was weaker than those with temperature (Figure $6 \mathrm{~d}, R=0.68, p<0.01$ ). 
(a) CCA pattern of temperature

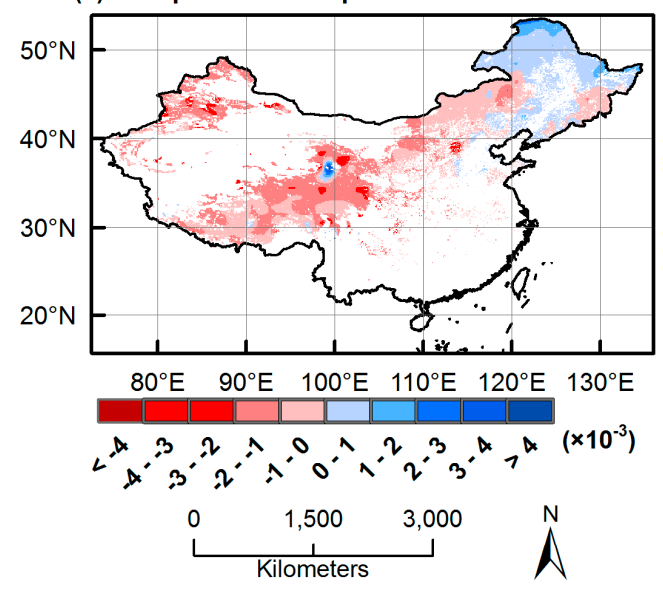

(c) CCA pattern of precipitation

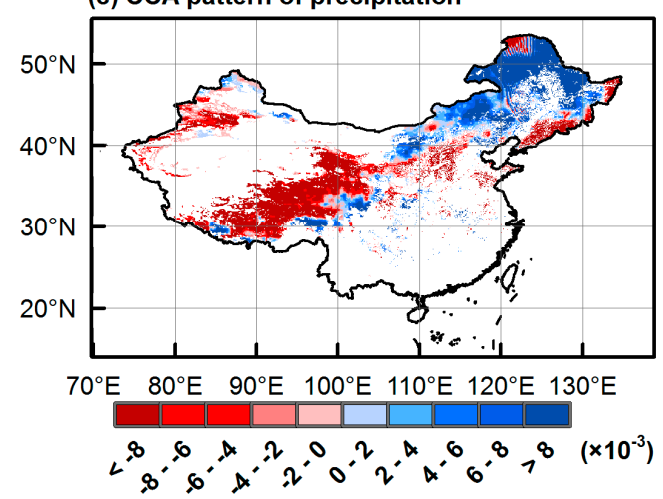

(b) CCA coefficients of EOS and T

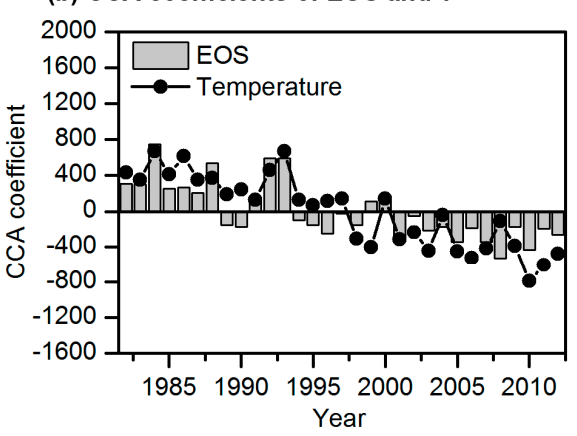

(d) CCA coefficients of EOS and P

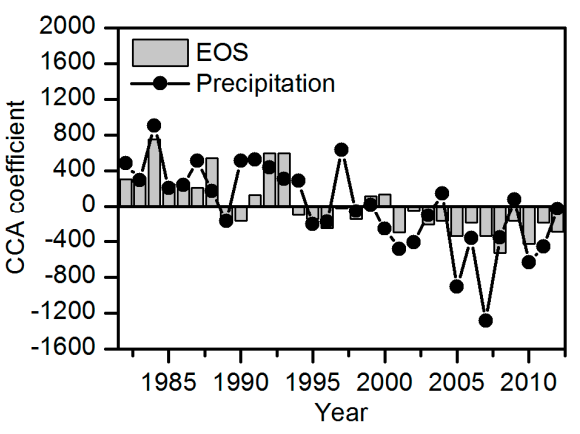

Figure 6. The CCA patterns and time coefficients between climate variables and EOS. (a) First CCA pattern of preseason temperature when performing CCA between EOS and preseason temperature; CCA pattern of EOS corresponding with pattern of temperature is shown in Figure 3c; (b) CCA time coefficients of EOS and preseason temperature $(R=0.79, p<0.01)$; (c) First CCA pattern of preseason precipitation when performing CCA between EOS and preseason precipitation; CCA pattern of EOS corresponding with pattern of precipitation is shown in Figure 3c; (d) CCA time coefficients of EOS and preseason precipitation $(R=0.68, p<0.01)$. The CCA weights and time coefficients are dimensionless parameters. The products of CCA weights and time coefficients are the phenological anomalies (days).

\section{Discussion}

Previous studies used EOF analysis to identify the most dominant pattern of year-to-year variability in spring phenophases based on species-level observation data. However, limited studies have applied it to satellite-derived phenology at the landscape level. The results of this study proved that the EOF analysis method was also able to diagnose the main spatial pattern in phenological variability at a larger spatial scale, despite the fact that the study area crossed various climate zones and vegetation types. The leading EOF modes of SOS and EOS in China revealed consistent advance or delay in phenophases over a broad region, which implied that there is synchronism among different vegetation types in phenological variation. This conclusion may be a result of phenological change at the species level, because many studies found that different individuals of the same or different species have the common variability of phenophases across geographical regions or ecosystems [47-49].

Although the SOS in China occurred relatively later from 2009 to 2012, the overall linear trend in SOS over the past 30 years still advanced at a rate of 0.6 days per decade. Similar shifts towards earlier SOS have also been reported by other phenological studies based on satellite data $[18,50,51]$. For example, Cong et al. [18] found that the vegetation green-up onset date advanced at the rate ranging from 0.4 to 1.9 days per decade (depending on the methods used) over temperate China in 
the period 1982-2010. In a recent meta-analysis of trends among Chinese plant phenophases, the spring phenophases of woody and herbaceous plants also advanced over the past several decades [3], suggesting that the variability of plant phenophases as seen from the ground is in accordance with the spatially integrated date of SOS observed from space.

Regarding the EOS, the PC of leading EOF mode was shown to be profoundly delayed in recent years, mainly after 1993, when a clear shift toward later EOS occurred. Few studies have focused on the change in autumn vegetation phenology at the landscape level in China. One earlier study indicated that the onset date of dormancy of China's temperate vegetation was delayed in autumn by 3.7 days per decade from 1982 to 1999 [37]. Another study found that the autumn vegetation dormancy onset date over China's temperate ecosystems was delayed by 0.13 days per year from 1982 to 2010 [19]. Therefore, the magnitudes of trends found in previous studies were stronger than our estimate ( 0.7 days per decade). The first reason for this is the impact of time periods on trend estimation [52], as our study extended the data series to 2012. In addition, trend values depended highly on phenophase retrieval methods [18]. In contrast to the Midpoint method applied in this study, Piao et al. [37] and Yang et al. [19] used polynomial function to reconstruct continuous NDVI series, and then determined the SOS or EOS threshold by the timing of the greatest relative change in multiyear averaged NDVI series. This discrepancy in method selection among different studies caused the difference in phenological trends.

The relationship between annual variability in the SOS and preseason climate variables was investigated through CCA. Similar to the results based on ground phenophase observation $[53,54]$, the results of CCA revealed a strong correlation between large-scale temperature and SOS variability in China. Both the time evolution and the spatial pattern of the first CCA mode of temperature were very similar to those of the SOS. Across the whole country, higher spring temperature corresponds to earlier SOS, which was in accordance with the results of a great number of phenological studies [4,55-57]. Compared to temperature, precipitation plays a second role in modulating the SOS, as the correlation between CCA time coefficients of the SOS and precipitation was weaker than those with temperature. When comparing CCA patterns of the SOS and precipitation, we found that the role of precipitation in regulating SOS varied among different vegetation types. For steppe and meadow on the Inner Mongolia and the Tibetan Plateau, and desert vegetation in Northwestern China, more rainfall was associated with advanced SOS, as reflected in most pixels (70\%). However, for other vegetation types, the response of SOS to precipitation was not so uniform. Such impact of precipitation on SOS in water-limited ecosystems can be anticipated because rainfall cues plant growth and development in arid and semiarid regions over the year [58-60].

The rapid climate change and its impacts on SOS of alpine ecosystems in the Tibetan Plateau are matters of global concern [50,61]. One recent study based on satellite-derived data pointed out that SOS is more sensitive to variations in preseason temperature in wetter than in dryer areas of the plateau [62]. Another study based on ground observation found that the correlation between preseason temperature and SOS was negative for most sites and species in the Tibetan Plateau, while the relationship between green-up dates and monthly precipitation series was less-pronounced and uncertain [63]. All these conclusions agreed with our results, i.e. warming would cause earlier SOS in the Tibetan Plateau, while increased preseason precipitation would promote the onset of green-up especially in arid areas. However, due to the fact that increased preseason precipitation may cause lower temperatures by accompanying deficient sunshine intensity and duration, later SOS may also be expected [62,64].

The interannual variance of EOS was associated with interannual change in temperature. The CCA patterns of EOS and temperature revealed that colder autumn temperatures were linked to earlier EOS in most areas of temperate China. In other words, higher temperature would lead to later EOS, which was consistent with other studies $[12,19,65]$. In comparison to temperature, preseason precipitation accounted for a smaller proportion of variance in EOS patterns. When comparing the CCA pattern of precipitation and EOS, it was found that less rainfall in autumn would lead to earlier EOS in 
northwestern China, where desert vegetation is distributed. Such a significant positive correlation between EOS of desert vegetation and precipitation was also reported by Piao et al. [37]. For other vegetation types, no consistent relationship was found between rainfall and EOS anomalies, which implied that rainfall was not a factor in regulating their EOS. Indeed, the leaf senescence process is mainly affected by two environmental factors: photoperiod and temperature, especially for vegetation under no drought stress [66,67].

\section{Conclusions}

In this study, we employed the empirical orthogonal function (EOF) analysis to assess the variability of satellite-derived growing season during the period of 1982-2012. The results showed that the first EOF mode was dominated by a relatively homogeneous structure, i.e. an earlier or later start of season (SOS) and end of season (EOS) for almost the whole country. The SOS times have become earlier since 1996, but began occurring later in the most recent four-year study period (2009-2012), whereas the EOS times have arrived later since 1993. Furthermore, the phenophases and climate variables (including preseason temperature and precipitation) were analyzed using canonical correlation analysis (CCA) to identify their common variance. The first pair of CCA patterns for phenological and preseason temperature were found to be very similar with the correlation coefficient between their time coefficients greater than 0.7. The impact of rainfall on SOS and EOS was of less importance, because correlation coefficients between CCA time coefficients of phenophases and preseason precipitation are weaker. Nonetheless, the role of rainfall in accelerating vegetation development was notable in water-limited areas. These results indicate that the large-scale variability in phenology could be explained to a great extent by the interannual variability of temperature and precipitation.

Overall, our results highlighted that natural vegetation in China exhibits a consistent signal of phenological shifts in its dominant EOF modes, even if the study regions were across various climate and vegetation zones. The similar CCA patterns and time coefficients between phenophases and preseason temperature indicate that land surface phenology (LSP) can serve as a reliable indicator for assessing the impact of climate change. Since the signal of phenological shifts was substantially inconsistent in other EOF modes, further research is needed to examine in detail the correlation between phenological metrics and other climate variables in specific climate or vegetation zones.

Acknowledgments: This research was supported by National Major Scientific Instruments Development Project (No.: 41427805), National Basic Research Program of China (No.: 2012CB955304).

Author Contributions: Huanjiong Wang had the original idea for the study. Quansheng Ge, Junhu Dai and Huijuan Cui helped with the analysis and interpretation of data. Huanjiong Wang drafted the manuscript, which was revised by all authors.

Conflicts of Interest: The authors declare no conflict of interest.

\section{References}

1. Sultan, S.E. Phenotypic plasticity for plant development, function and life history. Trends Plant Sci. 2000, 5, 537-542. [CrossRef]

2. Schwartz, M.D. Phenology: An Integrative Environmental Science, 2nd ed.; Springer Netherlands: Dordrecht, The Netherlands, 2013; pp. 1-2.

3. Ge, Q.; Wang, H.; Rutishauser, T.; Dai, J. Phenological response to climate change in China: A meta-analysis. Glob. Change Biol. 2015, 21, 265-274. [CrossRef] [PubMed]

4. Menzel, A.; Sparks, T.H.; Estrella, N.; Koch, E.; Aasa, A.; Ahas, R.; Alm-kübler, K.; Bissolli, P.; Braslavská, O.; Briede, A.; et al. European phenological response to climate change matches the warming pattern. Glob. Change Biol. 2006, 12, 1969-1976. [CrossRef]

5. Chambers, L.E.; Altwegg, R.; Barbraud, C.; Barnard, P.; Beaumont, L.J.; Crawford, R.J.M.; Durant, J.M.; Hughes, L.; Keatley, M.R.; Low, M.; et al. Phenological Changes in the Southern Hemisphere. PLoS ONE 2013, 8. [CrossRef] [PubMed] 
6. Gill, A.L.; Gallinat, A.S.; Sanders-DeMott, R.; Rigden, A.J.; Gianotti, D.J.S.; Mantooth, J.A.; Templer, P.H. Changes in autumn senescence in northern hemisphere deciduous trees: A meta-analysis of autumn phenology studies. Ann. Bot. Lond. 2015, 116, 875-888. [CrossRef] [PubMed]

7. Peñuelas, J.; Rutishauser, T.; Filella, I. Phenology feedbacks on climate change. Science 2009, 324, 887-888. [CrossRef] [PubMed]

8. Morisette, J.T.; Richardson, A.D.; Knapp, A.K.; Fisher, J.I.; Graham, E.A.; Abatzoglou, J.; Wilson, B.E.; Breshears, D.D.; Henebry, G.M.; Hanes, J.M.; et al. Tracking the rhythm of the seasons in the face of global change: Phenological research in the 21st century. Front. Ecol. Environ. 2008, 7, 253-260. [CrossRef]

9. Richardson, A.D.; Keenan, T.F.; Migliavacca, M.; Ryu, Y.; Sonnentag, O.; Toomey, M. Climate change, phenology, and phenological control of vegetation feedbacks to the climate system. Agric. For. Meteorol. 2013, 169, 156-173. [CrossRef]

10. Schwartz, M.D.; Hanes, J.M.; Liang, L. Comparing carbon flux and high-resolution spring phenological measurements in a northern mixed forest. Agric. Forest Meteorol. 2013, 169, 136-147. [CrossRef]

11. Keenan, T.F.; Gray, J.; Friedl, M.A.; Toomey, M.; Bohrer, G.; Hollinger, D.Y.; Munger, J.W.; O'Keefe, J.; Schmid, H.P.; Wing, I.S.; et al. Net carbon uptake has increased through warming-induced changes in temperate forest phenology. Nat. Clim. Change 2014, 4, 598-604. [CrossRef]

12. Richardson, A.D.; Andy Black, T.; Ciais, P.; Delbart, N.; Friedl, M.A.; Gobron, N.; Hollinger, D.Y.; Kutsch, W.L.; Longdoz, B.; Luyssaert, S.; et al. Influence of spring and autumn phenological transitions on forest ecosystem productivity. Philos. Trans. Royal Soc. B Biol. Sci. 2010, 365, 3227-3246. [CrossRef] [PubMed]

13. Cleland, E.E.; Chuine, I.; Menzel, A.; Mooney, H.A.; Schwartz, M.D. Shifting plant phenology in response to global change. Trends Ecol. Evol. 2007, 22, 357-365. [CrossRef] [PubMed]

14. Studer, S.; Stöckli, R.; Appenzeller, C.; Vidale, P.L. A comparative study of satellite and ground-based phenology. Int. J. Biometeorol. 2007, 51, 405-414. [CrossRef] [PubMed]

15. Schwartz, M.D.; Hanes, J.M. Intercomparing multiple measures of the onset of spring in eastern North America. Int. J. Climatol. 2010, 30, 1614-1626. [CrossRef]

16. Reed, B.C.; Schwartz, M.D.; Xiao, X. Remote sensing phenology. In Phenology of Ecosystem Processes; Noormets, A., Ed.; Springer New York: New York, NY, USA, 2009; pp. 231-246.

17. Hanes, J.; Liang, L.; Morisette, J. Land Surface Phenology. In Biophysical Applications of Satellite Remote Sensing; Hanes, J.M., Ed.; Springer: Berlin, Germany, 2014; pp. 99-125.

18. Cong, N.; Wang, T.; Nan, H.; Ma, Y.; Wang, X.; Myneni, R.B.; Piao, S. Changes in satellite-derived spring vegetation green-up date and its linkage to climate in China from 1982 to 2010: A multimethod analysis. Global Change Biol. 2013, 19, 881-891. [CrossRef] [PubMed]

19. Yang, Y.; Guan, H.; Shen, M.; Liang, W.; Jiang, L. Changes in autumn vegetation dormancy onset date and the climate controls across temperate ecosystems in China from 1982 to 2010. Global Change Biol. 2015, 21, 652-665. [CrossRef] [PubMed]

20. Garonna, I.; de Jong, R.; de Wit, A.J.W.; Mücher, C.A.; Schmid, B.; Schaepman, M.E. Strong contribution of autumn phenology to changes in satellite-derived growing season length estimates across Europe (1982-2011). Glob. Change Biol. 2014, 20, 3457-3470. [CrossRef] [PubMed]

21. Zhu, W.; Tian, H.; Xu, X.; Pan, Y.; Chen, G.; Lin, W. Extension of the growing season due to delayed autumn over mid and high latitudes in North America during 1982-2006. Glob. Ecol. Biogeogr. 2012, 21, 260-271. [CrossRef]

22. Hoscilo, A.; Balzter, H.; Bartholome, E.; Boschetti, M.; Brivio, P.A.; Brink, A.; Clerici, M.; Pekel, J.F. A conceptual model for assessing rainfall and vegetation trends in sub-Saharan Africa from satellite data. Int. J. Climatol. 2015, 35, 3582-3592. [CrossRef]

23. Wang, X.; Piao, S.; Xu, X.; Ciais, P.; MacBean, N.; Myneni, R.B.; Li, L. Has the advancing onset of spring vegetation green-up slowed down or changed abruptly over the last three decades? Glob. Ecol. Biogeogr. 2015, 24, 621-631. [CrossRef]

24. Zhang, X.; Tan, B.; Yu, Y. Interannual variations and trends in global land surface phenology derived from enhanced vegetation index during 1982-2010. Int. J. Biometeorol. 2014, 58, 547-564. [CrossRef] [PubMed]

25. Jeong, S.; Ho, C.; Gim, H.; Brown, M.E. Phenology shifts at start vs. end of growing season in temperate vegetation over the Northern Hemisphere for the period 1982-2008. Glob. Change Biol. 2011, 17, 2385-2399. [CrossRef] 
26. Shen, M.; Tang, Y.; Chen, J.; Yang, X.; Wang, C.; Cui, X.; Yang, Y.; Han, L.; Li, L.; Du, J.; et al. Earlier-Season Vegetation Has Greater Temperature Sensitivity of Spring Phenology in Northern Hemisphere. PLoS ONE 2014, 9. [CrossRef] [PubMed]

27. Cayan, D.R.; Kammerdiener, S.A.; Dettinger, M.D.; Caprio, J.M.; Peterson, D.H. Changes in the onset of spring in the western United States. Bull. Am. Meteorol. Soc. 2001, 82, 399-416. [CrossRef]

28. Studer, S.; Appenzeller, C.; Defila, C. Inter-annual variability and decadal trends in alpine spring phenology: A multivariate analysis approach. Clim. Change 2005, 73, 395-414. [CrossRef]

29. Zhao, S. Physical Geography of China; Science Press: Beijing, China, 1986; pp. 1-209.

30. Asrar, G.; Fuchs, M.; Kanemasu, E.T.; Hatfield, J.L. Estimating absorbed photosynthetic radiation and leaf area index from spectral reflectance in wheat. Agron. J. 1984, 76, 300-306. [CrossRef]

31. White, M.A.; Thornton, P.E.; Running, S.W. A continental phenology model for monitoring vegetation responses to interannual climatic variability. Glob. Biogeochem. Cycles 1997, 11, 217-234. [CrossRef]

32. Schwartz, M.D.; Reed, B.C.; White, M.A. Assessing satellite-derived start-of-season measures in the conterminous USA. Int. J. Climatol. 2002, 22, 1793-1805. [CrossRef]

33. Pinzon, J.E.; Tucker, C.J. A Non-Stationary 1981-2012 AVHRR NDVI3g Time Series. Remote Sens. 2014, 6, 6929-6960. [CrossRef]

34. Editorial Board of the Vegetation Map of China. Vegetation Map of the People's Republic of China (1: 10,000,000); Geological Publishing House: Beijing, China, 2007.

35. He, J.; Yang, K. China Meteorological Forcing Dataset. Cold Arid Reg. Sci. Data Cent. Lanzhou 2011. [CrossRef]

36. Shen, M.; Tang, Y.; Chen, J.; Zhu, X.; Zheng, Y. Influences of temperature and precipitation before the growing season on spring phenology in grasslands of the central and eastern Qinghai-Tibetan Plateau. Agric. Forest Meteorol. 2011, 151, 1711-1722. [CrossRef]

37. Piao, S.L.; Fang, J.Y.; Zhou, L.M.; Ciais, P.; Zhu, B. Variations in satellite-derived phenology in China's temperate vegetation. Glob. Change Biol. 2006, 12, 672-685. [CrossRef]

38. White, M.A.; De Beurs, K.M.; Didan, K.; Inouye, D.W.; Richardson, A.D.; Jensen, O.P.; O’Keefe, J.; Zhang, G.; Nemani, R.R.; van Leeuwen, W.J.D.; et al. Intercomparison, interpretation, and assessment of spring phenology in North America estimated from remote sensing for 1982-2006. Glob. Change Biol. 2009, 15, 2335-2359. [CrossRef]

39. Wang, H.; Dai, J.; Ge, Q. Comparison of satellite and ground-based phenology in China's temperate monsoon area. Adv. Meteorol. 2014, 2014, 1-10. [CrossRef]

40. Schaber, J.; Badeck, F.W. Evaluation of methods for the combination of phenological time series and outlier detection. Tree Physiol. 2002, 22, 973-982. [CrossRef] [PubMed]

41. Wang, T.; Ottlé, C.; Peng, S.; Janssens, I.A.; Lin, X.; Poulter, B.; Yue, C.; Ciais, P. The influence of local spring temperature variance on temperature sensitivity of spring phenology. Glob. Change Biol. 2014, 20, 1473-1480. [CrossRef] [PubMed]

42. Menzel, A. Plant phenological anomalies in Germany and their relation to air temperature and NAO. Clim. Change 2003, 57, 243-263. [CrossRef]

43. Bolmgren, K.; Vanhoenacker, D.; Miller-Rushing, A.J. One man, 73 years, and 25 species. Evaluating phenological responses using a lifelong study of first flowering dates. Int. J. Biometeorol. 2013, 57, 367-375. [CrossRef] [PubMed]

44. Bretherton, C.S.; Smith, C.; Wallace, J.M. An intercomparison of methods for finding coupled patterns in climate data. J. Climate 1992, 5, 541-560. [CrossRef]

45. Hotelling, H. Relations between two sets of variates. Biometrika 1936, 28, 321-377. [CrossRef]

46. Von Storch, H. Spatial patterns: EOFs and CCA. In Analysis of Climate Variability; von Storch, H., Navarra, A., Eds.; Springer: Berlin, Germany; Heidelberg, Germany, 1999; pp. 231-263.

47. Franklin, D.C.; Bach, C.S. Assessing intraspecific phenological synchrony in zoochorous trees from the monsoon forests of northern Australia. J. Trop. Ecol. 2006, 22, 419-429. [CrossRef]

48. Sparks, T.H.; Mizera, T.; Wojtowicz, W.; Tryjanowski, P. Synchrony in the phenology of a culturally iconic spring flower. Int. J. Biometeorol. 2012, 56, 407-409. [CrossRef] [PubMed]

49. Rutishauser, T.; Luterbacher, J.; Jeanneret, F.; Pfister, C.; Wanner, H. A phenology-based reconstruction of interannual changes in past spring seasons. J. Geophys. Res. 2007, 112. [CrossRef]

50. Zhang, G.; Zhang, Y.; Dong, J.; Xiao, X. Green-up dates in the Tibetan Plateau have continuously advanced from 1982 to 2011. Proc. Nat. Acad. Sci. USA 2013, 110, 4309-4314. [CrossRef] [PubMed] 
51. Wu, X.; Liu, H. Consistent shifts in spring vegetation green-up date across temperate biomes in China, 1982-2006. Glob. Change Biol. 2013, 19, 870-880. [CrossRef] [PubMed]

52. Parmesan, C. Influences of species, latitudes and methodologies on estimates of phenological response to global warming. Global Change Biol. 2007, 13, 1860-1872. [CrossRef]

53. Chmielewski, F.; Rötzer, T. Annual and spatial variability of the beginning of growing season in Europe in relation to air temperature changes. Clim. Res. 2002, 19, 257-264. [CrossRef]

54. Liu, G.; Tang, Q.; Liu, X.; Dai, J.; Zhang, X.; Ge, Q.; Tang, Y. Spatiotemporal analysis of ground-based woody plant leafing in response to temperature in temperate eastern China. Int. J. Biometeorol. 2014, 58, 1583-1592. [CrossRef] [PubMed]

55. Badeck, F.W.; Bondeau, A.; Böttcher, K.; Doktor, D.; Lucht, W.; Schaber, J.; Sitch, S. Responses of spring phenology to climate change. New Phytol. 2004, 162, 295-309. [CrossRef]

56. Wolkovich, E.M.; Cook, B.I.; Allen, J.M.; Crimmins, T.M.; Betancourt, J.L.; Travers, S.E.; Pau, S.; Regetz, J.; Davies, T.J.; Kraft, N.; et al. Warming experiments underpredict plant phenological responses to climate change. Nature 2012, 485, 494-497. [CrossRef] [PubMed]

57. Zheng, J.; Ge, Q.; Hao, Z.; Wang, W.C. Spring phenophases in recent decades over eastern China and its possible link to climate changes. Clim. Change 2006, 77, 449-462. [CrossRef]

58. Schmidt, H.; Karnieli, A. Remote sensing of the seasonal variability of vegetation in a semi-arid environment. J. Arid Environ. 2000, 45, 43-59. [CrossRef]

59. Zhang, X.; Friedl, M.A.; Schaaf, C.B.; Strahler, A.H.; Liu, Z. Monitoring the response of vegetation phenology to precipitation in Africa by coupling MODIS and TRMM instruments. J. Geophys. Res. Atmos. 2005, 110. [CrossRef]

60. Dalmolin, A.N.C.; de Almeida, L.F.; Vourlitis, G.; Silva, P.R.; Dalmagro, H.J.E.; Antunes, M.Z.E.A., Jr.; Ortiz, C.E.R. Is the dry season an important driver of phenology and growth for two Brazilian savanna tree species with contrasting leaf habits? Plant Ecol. 2015, 216, 407-417. [CrossRef]

61. Yu, H.; Luedeling, E.; Xu, J. Winter and spring warming result in delayed spring phenology on the Tibetan Plateau. Proc. Nat. Acad. Sci. USA 2010, 107, 22151-22156. [CrossRef] [PubMed]

62. Shen, M.; Piao, S.; Cong, N.; Zhang, G.; Jassens, I.A. Precipitation impacts on vegetation spring phenology on the Tibetan Plateau. Global Change Biol. 2015, 21, 3647-3656. [CrossRef] [PubMed]

63. Chen, X.; An, S.; Inouye, D.; Schwartz, M. Temperature and snowfall trigger alpine vegetation green-up on the world's roof. Global Change Biol. 2015, 21, 3635-3646. [CrossRef] [PubMed]

64. Wang, H.; Liu, D.; Lin, H.; Montenegro, A.; Zhu, X. NDVI and vegetation phenology dynamics under the influence of sunshine duration on the Tibetan plateau. Int. J. Climatol. 2015, 35, 687-698. [CrossRef]

65. Dai, J.; Wang, H.; Ge, Q. The spatial pattern of leaf phenology and its response to climate change in China. Int. J. Biometeorol. 2014, 58, 521-528. [CrossRef] [PubMed]

66. Vitasse, Y.; François, C.; Delpierre, N.; Dufrêne, E.; Kremer, A.; Chuine, I.; Delzon, S. Assessing the effects of climate change on the phenology of European temperate trees. Agric. Forest Meteorol. 2011, 151, 969-980. [CrossRef]

67. Estrella, N.; Menzel, A. Responses of leaf colouring in four deciduous tree species to climate and weather in Germany. Clim. Res. 2006, 32, 253-267. [CrossRef]

(C) 2016 by the authors; licensee MDPI, Basel, Switzerland. This article is an open access article distributed under the terms and conditions of the Creative Commons Attribution (CC-BY) license (http://creativecommons.org/licenses/by/4.0/). 